\section{Authors' response: Long-term lung function in postinfectious bronchiolitis obliterans}

Dear editors

We thank Drs Rosewich, Eckrich and Zielen for their interest and comments ${ }^{1}$ on our recent Thorax publication. ${ }^{2}$

We entirely agree that lung growth is clearly related to somatic growth. The main focus of the paper was based on the data obtained from 200 spirometries and not in lung volumes because they were not available in all patients.

There is no contradiction between the rise in FVC and $\mathrm{FEV}_{1}$ values and the conclusion that pulmonary function remained severely impaired. As patients had an extremely low initial lung function, despite their increment, lung function remains extremely low. Moreover, an annual decrease in percentage of theoretical values of total lung capacity and residual volume $(12 \pm 4 \%$ and $12 \pm$ $11.6 \% /$ year, respectively) was observed.

We understand that there are different ways to inform lung function related to growth. Based on our large data obtained after a 12-year follow-up period and in order to be as clear as possible, we decided to analyse it using generalised linear mixed effects models, as shown in figure 1 in the paper. We presented the data of the lung function as a relationship between pulmonary function values and the development of height to show that FVC and $\mathrm{FEV}_{1}$ values increased at the same time as they grew up from 5 to 20 years of age. This way of showing the data emphasises that lung growth is clearly related to somatic growth, thereby avoiding misunderstanding. This study allows us to determine the annual rate of $\mathrm{FEV}_{1}$ and $\mathrm{FVC}$ growth as it was done for other chronic lung diseases like bronchopulmonary dysplasia. ${ }^{3}$

\section{Alejandro Colom, ${ }^{1}$ Alberto Maffey, ${ }^{1}$} Facundo Garcia Bournissen, ${ }^{2}$ Alejandro Teper ${ }^{1}$

${ }^{1}$ Respiratory Center, R. Gutierrez Children's Hospital, Buenos Aires, Argentina

${ }^{2}$ Parasitology and Chagas Service, R. Gutierrez

Children's Hospital, Buenos Aires, Argentina

Correspondence to Dr Alejandro Colom, Respiratory Center, R. Gutierrez Children's Hospital, España 880, San Miguel (1663), Buenos Aires, Argentina; acolom@gmail.com

Contributors All authors made substantial contributions to drafting the work or revising it critically for important intellectual content and final approval of the version to be published.

Competing interests None declared.
Provenance and peer review Not commissioned; internally peer reviewed.

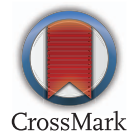

To cite Colom A, Maffey A, Garcia Bournissen F, et al. Thorax 2015;70:793.

Received 30 March 2015

Accepted 2 April 2015

Published Online First 7 May 2015

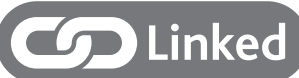

http://dx.doi.org/10.1136/thoraxjnl-2015-206998

Thorax 2015;70:793.

doi:10.1136/thoraxjnl-2015-207112

\section{REFERENCES}

1 Martin Rosewich M, Eckrich J, Zielen S. Long term lung function in postinfectious bronchiolitis obliterans. Thorax 2015;70:792.

2 Colom AJ, Maffey A, Bournissen FG, et al. Pulmonary function of a paediatric cohort of patients with postinfectious bronchiolitis obliterans. A long term follow-up. Thorax 2015;70:169-74.

3 Filippone M, Bonetto G, Cherubin E, et al. Childhood course of lung function in survivors of bronchopulmonary dysplasia. JAMA 2009;302:1418-20. 